\title{
A Propósito do Segredo
}

\author{
Jean Florence ${ }^{1}$ \\ Université Catholique de Louvain - Bélgica
}

\begin{abstract}
RESUMO - O artigo pretende estudar uma questão central da clínica psicanalítica e de qualquer outra psicoterapia: o segredo. Para tanto, o segredo é estudado em quatro etapas evocando algumas de suas dimensões: a história da palavra dentro da nossa linguagem; a questão do nascimento do pensamento e da psicose; as dramaturgias do segredo conforme alguns escritores; o paradoxo da famosa regra psicanalítica e suas conseqüências: o trabalho do segredo.
\end{abstract}

Palavras-chave: segredo; psicanálise; linguagem.

\section{On Secret}

\begin{abstract}
The article intends to study a central subject of the clinical psychoanalysis and of any other psychotherapy: the secret. For so much, the secret is studied in four stages evoking some of its dimensions: The history of the word inside our language; The subject of the birth of the thought and of the psychosis; The dramaturgies of the secret according to some writers; The paradox of the famous psychoanalytical rule and its consequences: the work of the secret.
\end{abstract}

Key words: secret; psychoanalysis; language.

Profissionais do encontro pessoal fundado em um contrato de confiança, somos nós, médicos, psicólogos, psicoterapeutas e psicanalistas instituídos os depositários de todos os tipos de segredos. Segredos confiados expressamente e tidos como tais pelos sujeitos, mas igualmente segredos liberados sem que eles desconfiem e nem possam medir a importância e o que está em jogo. Segredos ingênuos ou atordoadamente largados, segredos que tocam esses mesmos sujeitos na sua intimidade, ou segredos referentes a outras pessoas e dos quais eles não podem mais, por longo tempo, sustentar sozinhos o peso, a opressão, a tortura ou a vergonha.

Tornar-se o portador de um segredo pode certamente lisonjear, posto que dá um sentimento de ser escolhido, eleito e distinguido do comum entre os mortais que o ignoram, mas pode também pesar, embaraçar, dividir aquele que se encontra surpreso, visado, perseguido. Nossa prática retoma a seqüência da atividade secular da medicina de Hipócrates, conjuntamente com aquela dos pastores, dos padres e confessores, assim como aquela de altos secretários dos príncipes desse mundo...

O segredo diz respeito à ética e, por intermédio desse, o fundo do ser: a ontologia e a ontogênese; ele toca as formas mais essenciais da ligação com o Outro e a identidade pessoal; ele está mesmo à prova, tanto dentro dos relacionamentos privados quanto dentro da vida social, do poder que o homem possui sobre ele mesmo e sobre o outro: ele representa o que pode ser o mais precioso e o mais ameaçador.

$\mathrm{O}$ segredo toca as potencialidades do próprio desejo, dentro de suas intermitências, sua vulnerabilidade, seu vai e vem infinito, sua insuperável ambigüidade entre o dizer e o

1 Endereço: Psicanalista. Rue de Livourne, 152 B-1000 Bruxelas, Bélgica calar-se, entre a confissão e o silêncio, a consciência e a ignorância. Cômica, trágica, romanesca, a relação do homem com o segredo é profundamente paradoxal: paradoxo que se prende à natureza mesma da linguagem (se não fôssemos seres falantes não teríamos nada a ver com o segredo, nem com a mentira, nem com a verdade...). A linguagem é o secretário implacável do nosso ser, o único secretário que nós não poderíamos liberar ou licenciar sem incorrer em um perigo extremo (ainda que seja sempre perigoso demitir um(a) secretário(a)!).

Os poetas a enviaram a navegar nas águas agitadas e perturbadoras desse vasto paradoxo. Por sua vez, os psicanalistas, sem dúvida, de forma mais trivial, nadam nessas águas também por aí, sabendo que sua tomada de partido pelas virtudes da palavra não impede que o diálogo, em princípio, seja infinito (como diz Blanchot, 1968) e que, fosse ele finito, não daria nunca a última palavra do que somos, nem a palavra do fim...

\section{Os Segredos da Palavra "Segredo"}

Há uma "filosofia" dentro da própria linguagem, redes de significados. A história de uma palavra como a do "segredo" nos permitirá despertar para os seus vários sentidos, nos reavivando um universo, ou ainda mais, uma nebulosa de evocações que nos dispomos a introduzir nesta reflexão comum quanto ao segredo.

A palavra é derivada do latim secretu: um lugar à parte, pensamento ou acontecimento que não deve ser revelado, mistérios (de um culto religioso). Secretus, o adjetivo, significa solitário, separado, isolado, recluso, dissimulado e raro. O próprio verbo se-cernere, na origem desta palavra, é constituído do prefixo SE - marcando a separação e de CERNERE: selecionar, passar no crivo; de que lugar distinguir, discernir, 
ver, escolher, decidir (krinein em grego - krypto: esconder; cripta). Primeiros usos em francês: saber reservado a algumas pessoas, troca de conhecimentos reservados dados a título de conselho, um aviso dentro de um contexto político (secretário). Elementos da vida privada que não devem ser do conhecimento de todos. "Sob a chancela (real) do segredo": expressão originalmente política, tornou-se metáfora da confidência com a promessa de nada revelar. "Em segredo", em voz baixa (sussurro baixo). Destinada a designar por eufemismo certas coisas ou atividades: as partes sexuais (os segredos), as necessidades naturais (o segredo); "laisser un secret" (soltar um segredo) dizia-se divertidamente no século XVII para se dizer ter soltado um peido discreto. Um outro uso ainda: meio, processo, método, arte ou técnica que devem se tornar objeto de um ensinamento particular, de maneira iniciática: segredos de fabricação, segredo industrial.

É depois do século XVI, como atesta o dicionário histórico da língua francesa, Le Robert, (Robert, 1998), que o "conteúdo escondido" toma um valor psicológico, no sentido onde ele se aplica à interioridade da pessoa. O segredo propõe-se a designar a vida íntima e não revelada de alguém. As expressões parecem testemunho dessa acepção: "os segredos do coração", "ter o segredo de alguém", "confiar um segredo", "fazer parte do segredo". Como a informação que se pretende manter escondida ou reservada não o é para sempre, existem expressões desdenhosas, tais como: segredo de comédia (uma peça de teatro que o público pode entender), o segredo de Polichinelo (1808, este personagem grotesco da Commedia dell arte, sendo muito freqüentemente zombado, seus segredos não enganam mais). Sobre esse indivíduo, Arnaud Lévy (1976) nota que a locução pode ser interpretada de vários modos:

- Inicialmente, isso designa o segredo de Polichinelo para si mesmo (aquele que ele guarda) e o segredo que lhe concerne;

- "Ter um Polichinelo na gaveta" evoca o segredo de uma gravidez. Mas a criança não pode ser retida indefinidamente no ventre da mãe e o segredo não pode ser guardado;

- Polichinelo também quer dizer marionete, fantoche, aquele que não tem vontade própria: metáfora da relação primeira da mãe com a criança e do treinamento esfincteriano precoce - a criança é como se fosse agida por sua mãe (l'enfant est comme agi par sa mère) - estatuto de feto?

O mesmo Lévy (1976) utiliza as conotações semânticas da palavra "segredo" para meditar sobre a arqueologia ou a psicogênese "anal" do segredo. O segredo, sendo um saber dissimulado com o próximo é tratado sob o aspecto anal, isto quer dizer, dentro de uma relação de poder: largar, abandonar, realizar-se, submeter-se, dar liberdade ou recusar, reter em si mesmo qualquer coisa que tem valor em uma relação, que está em jogo, uma coisa preciosa e/ou coisa malvada, tesouro ou cocô. A partir do que - o que vai nos permitir ir a nosso segundo ponto - construir o que é denominado "próprio" na sua tríplice acepção: por oposição a sujo, no- jento, ruim; por oposição a estrangeiro (eu/não eu); por oposição a impróprio (conforme - não conforme).

O sujeito, como se sabe, pode ou não se tomar por um objeto anal (se é o que se faz). Há, portanto, para esse ator, na sua ótica psicogenética muito classicamente "analítica", uma relação, um laço entre segredo, secreção e excremento. Em outro nível, a ligação entre a separação (um bom objeto para guardar, para dar - mau objeto para rejeitar) e a metáfora do ato mental que instaura o segredo como aquilo que é apropriado, privado e pessoal, com toda a ambivalência voltada sobre o valor narcísico retendo esse segredo para o próprio indivíduo, e para o que ele oferece ou não de si mesmo a outro.

Para retornar à utilização da linguagem, deve-se ainda evocar o "segredo da confissão" (aproximadamente 1690) e retornaremos ainda sob o nos aproximar da análise e, certamente, o "segredo profissional" (1875). Além do mais, a questão do segredo profissional (para os médicos, os psicólogos) nos seus aspectos jurídicos, éticos e deontológicos, o que foi o ponto de partida desse presente ensaio sobre o segredo.

\section{O nascimento do pensamento}

\section{Qual foi o nosso primeiro segredo?}

As reflexões sobre o segredo de Polichinelo sugeriram que a primeira relação com o Outro é de posse ou identificação. Ainda que a idéia de que a criança, inicialmente agida por sua mãe, pensada por ela, só possa ser uma ficção, pergunto-me se desde os primeiros movimentos, mesmo que bastante desordenados, o bebê não age de uma forma primordial de querer pulsional que cria muito cedo na mãe o sentimento, meio agradável, meio decepcionante, de que este pequeno ser lhe "escapa". Poderia ela, além disso, adivinhar o sentido de todos os gritos do bebê? Ela dispõe de um enorme poder sobre seu bebê, mas que encontra de saída o seu limite: o que ele vai tomar ou rejeitar, guardar ou "devolver" daquilo que ela tanto quis lhe dar? A aprendizagem da limpeza é um "jogo"( match) (seguido, conforme o caso, de mais ou menos prolongações épicas) onde a criança colocaria o seu próprio poder, mais consciente, de se abrir ou de se fechar a esse Outro tão benevolente e tão exigente. A isso concilia-se a aprendizagem da língua, até que apareça um trovão que não passará desapercebido para ninguém: o primeiro não. Virá em seguida, um belo dia qualquer, a primeira mentira, de onde se adivinha a aposta extraordinária pelo sentimento de "si mesmo": posso fazer com que ela não saiba de mim, não sou transparente; ela procura me intimidar pretendendo e querendo me fazer crer que, caso eu dissimule qualquer coisa ou pensamento, meu nariz se esticará, ou de todo modo meu pequeno dedo vai lhe informar a dissimulação...

Compreende-se que certos analistas, principalmente estimulados pelo enigma da psicose, exploraram todos esses momentos essenciais, na gênese do indivíduo, quando a interação da criança com a mãe abre ou fecha, de modo mais ou menos anulante, os caminhos da liberdade: no mover, 
sentir, agir, fazer, pensar, desejar. No fundamento da experiência psicótica, não há esta perda da possibilidade de pensar secretamente? A possibilidade de dissimular, de fantasiar, de imaginar ficções não estará fundamentalmente ligada ao exercício, primordialmente concedido pela mãe, do prazer de pensar em segredo - prazer tão grande quanto aquele, que é seu corolário, de comunicar seus pensamentos? Os sintomas mais impressionantes da psicose (convicção do roubo do pensamento, compulsões que fazem pensar em idéias penosas, sentimento do vazio do pensamento ou da transparência em relação ao olhar dos outros) não seriam eles o testemunho da extraordinária luta que o sujeito trava para ganhar essa liberdade pela colocação em ato de um discurso completamente desligado de qualquer entrave sintático ou semântico, ou pela regressão à recusa autista de falar? Toda relação nova com o Outro (ao amor...) mobiliza em cada um essas importantes e originais provações em jogo, essa luta para "ex-sister" separado e religado ao outro.

\section{Dramaturgia do segredo: do lado dos poetas}

Só posso me permitir aqui fazer evocações que não terão somente função sugestiva... Todo escritor de alguma consistência já investigou e explorou o vasto mundo do segredo. As vicissitudes do amor são o próprio elemento no sentido quando se diz que encontra-se "bem no seu elemento". Nas águas do amor, o segredo está perfeitamente no seu elemento: ele multiplica todos os seus encantos, todos os seus ilusionismos, todos os seus golpes de magia, todos os seus artifícios e todos os seus poderios. Tomemos alguns escritores ao acaso: Diderot (Les bijoux indiscrets) - (As jóias indiscretas), Shakespeare (Beaucoup de bruit pour rien) (Muito barulho por nada), Marivaux, em todas suas comédias, Proust (A la recherche du temps perdu) - (À procura do tempo perdido), Hergé: (Le secret de la Licorne, Le trésor de Rackam le rouge...) - (O segredo do unicórnio, $\mathrm{O}$ tesouro de Rackam o vermelho...).

A linguagem obriga a nos tornarmos intérpretes, adivinhos, sonharmos que somos videntes, porque diante do segredo do outro, dispomos somente de signos: signos sensíveis, signos mundanos, signos mentirosos, signos artísticos... Quem procuraria a verdade se ela não tivesse sido apreendida precocemente, levada ao trabalho do pensamento, que todo gesto, toda entonação, toda saudação, toda palavra não exigissem ser interpretados? Quem procuraria a verdade caso ela não tivesse de início provado o sofrimento que dá opacidade do ser amado? Não seriam os poetas, aqueles que nos ensinam essa relação obstinada com os signos, por meio dessa promessa que os segredos da alma penetrarão um dia?

\section{O trabalho do segredo na psicanálise}

Deter-me-ei aqui a apontar o paradoxo essencial - e constitutivo - da regra fundamental que instaura a relação analítica: "Diga tudo o que lhe vem à cabeça, o mais sinceramente possível, sem fazer julgamentos de conveniência, moral, estética e intelectual (lógica) quanto ao que se apresenta aqui...".
A regra, simplificada ao extremo na expressão "dizer tudo" é, como bem sabe quem se arrisca a segui-la, impossível. E, certamente, ela suscita a entrada em jogo das resistências do dizer ele mesmo. Portanto, o neurótico comum aceita isso sem dano maior, mesmo se ele revela os ditos complexos originais que se constituem na vida inconsciente, os modos pelos quais nós tentamos "fixar" o outro dentro de uma relação determinada. A imposição dessa regra ao psicótico (borderline) pode criar uma angústia descontrolada nele mesmo, que receia e deseja ao mesmo tempo ser escutado, acreditado, reconhecido como existente sem risco de morte do seu pensamento. É necessário que todo analisando, qualquer que seja sua estrutura, se sinta, ao mesmo tempo, permitindo-se o direito de se calar.

A psicanálise não instaura uma relação nova com o segredo? Os Études sur l'hystérie (Estudos sobre a histeria) fizeram-nos descobrir que um acontecimento (ou uma sucessão de eventos) de alta intensidade emocional, na qual o indivíduo só pôde significar e reconhecer o caráter chocante, traumático, insuportável por razões de uma obrigação, tornou-se "segredo" e que, longe de ser esquecido nesse estado de recalque, exerce sua influência na produção dos sintomas de conversão. O sintoma histérico aparece como a tentativa de guardar o segredo, sem conseguir conter a violência da qual é um portador.

Mas, a histeria é também o modelo do retorno do recalcado sob todas as formas enigmáticas que o inconsciente pode urdir. O sintoma pode, então, não ser mais somente o signo de uma doença, um déficit, uma degeneração, uma lesão ou uma perda de função; ele torna-se significante, polissêmico, traço, memória ou monumento: símbolo de uma intensa atividade, exigindo uma enorme energia de dissimulação, de transposição e apagamento nunca totalmente bem sucedidos. Como o sintoma, para Breuer e para Freud (1895/ 1965), toma o valor de uma palavra que não pode se dizer, de uma voz que foi sufocada, torna-se o parceiro positivo do trabalho analítico. E esse trabalho libera de fato os segredos: segredos de família, segredos de alcova, segredos de amor. Até que Freud se ponha a duvidar da realidade das cenas e descobre o impacto da atividade da fantasia (das Phantasieren) que coloca doravante a atividade do segredo (esconder - desvelar) dentro de uma relação real (traumática), imaginária (fantástica, fantasista, romanesca, legendária, mítica) e de estruturas simbólicas de interlocuções ( as leis e os interditos, as obrigações, as convenções da linguagem e as imposições intersubjetivas da fala).

A cura analítica pôde ser comparada com a confissão. Mas Freud (1965) notou que é mais difícil confessar seus fantasmas que seus pecados. Estes são de alguma maneira catalogados e, mais ainda, as penitências infligidas são proporcionais a seu grau de gravidade. Ocorre de outro modo com os fantasmas que não são somente os "maus pensamentos", mas os pensamentos impostos, que sobrevêm não se sabe de onde, estranhos, sedutores, inquietantes e atemorizantes. $\mathrm{O}$ fantasma é um produto misto, tecido de consciente e inconsciente, uma formação intermediária onde a ficção confunde-se com as recordações, do arcaico ao atual, do 
ancestral ao individual. Ocorre então, o segredo, voluntariamente mantido como segredo, e os segredos inconscientes dos quais o sujeito ignora ser o detentor ou o depositário.

A experiência analítica convida-nos ainda a considerar dois aspectos fundamentais do segredo: a psicose leva ao reconhecimento da necessidade vital de um sujeito constituir uma parte secreta, protegida do outro onipotente, isso conduz a uma reflexão fundamental quanto à função do recalque primário; a neurose convida a levar em conta os efeitos negativos de certos segredos ligados ao romance familiar ou às realidades traumáticas da vida em família.

Restaria investigar o vasto problema da ética do segredo profissional na prática analítica, mas sobretudo quando a questão do segredo torna-se crucial e conflitante, na prática institucional quando os imperativos terapêuticos cruzam-se com os imperativos de uma outra ordem: administrativa, médico-legal e judiciária. Mas, talvez a abordagem dessas questões do segredo poderia tirar proveito de uma reflexão preliminar sobre as dimensões daquele, reflexão esta que essas páginas propuseram-se a introduzir.

Deixemos ao poeta o cuidado de nos substituir nessas questões. As anotações de Paul Valéry (1970) em Tel Quel, como veremos, não são sem ressonância com o que precede:

Os homens distinguem-se por aquilo que mostram e assemelham-se por aquilo que escondem;

O amor endereça-se a quem está dissimulado no seu objeto... Eu te amo e portanto não te conheço...( p. 306)

Ou ainda, a propósito de duas palavras que expressam tão justamente as contradições do segredo: o inacessível e o inapreensível:
O que há portanto de tão precioso em nós que não poderíamos abandonar aos padres, às serpentes, à doçura evangélica, aos mandamentos dos profetas, aos [chicotes], aos sofrimentos de Cristo? Quem resiste às ameaças mais graves, às promessas mais vastas, aos milagres e mesmo às tentações?...( p. 308)

Existe aquilo que não conheço, que nós não cedemos e não cederíamos nunca, porque nada pode substituir, ganhar, abolir, valer aquilo que faz que sejamos o que somos, e que não se troca por nada, ainda que aquilo possa tornar-se nada...(p. 350)

\section{Referências}

Blanchot, M. (1968). L'entretien infini. Paris: Gallimard.

Castoriadis-Aulagnier, P. (1976). Le droit au secret: Condition pour pouvoir penser. Nouvelle revue de psychanalyse, 14, 141-158.

Deleuze, G. (1965). Proust et les signes. Paris: PUF.

Robert, P. (Org.). (1998). Le Robert. Dictionnaire historique de la langue française ( $7^{\mathrm{a}}$ ed., Vols. 1-2). Paris: Robert.

Lévy, A. (1976). Évaluation étymologique et sémantique du mot secret. Nouvelle revue de psychanalyse, 14, 117-129.

Tisseron, S. (1994). "L'héritage insu: lês secrets de famille". Communications - Genération et Filiation, 59, 29-38.

Valéry, P. (1970). Tel quel. Em Oeuvres Complètes (p. 58). Paris: Gallimard.

Freud, S. \& Breuer, S. (1965). Études sur l'hystérie (A. Berman, Trad.). Em J. Strachey (Org.), Obras Completas de Sigmund Freud (Volume II, pp. 36-82). Paris: PUF. (Trabalho original publicado em 1895) 